\title{
VAI TRÒ CỦA LƯU LƯợG MÁU TÙ THẤT LÊN ĐỘNG MẠCH PHỔI TRONG PHẪU THUẬT FONTAN VỚI ĐƯờnG DÃ̂N MÁU NGOÀI TIM BẰNG ỐNG GHÉP NHÂN TẠO
}

\section{TÓM TẮT}

Đặt vấn đề: Trong phẫu thuật Fontan cho bệnh tim một tâm thất chức năng, vai trò của lưu lượng máu từ thất lên động mạch phổi vẫn còn nhiều bàn luận về hiệu quả và ảnh hưởng đến kết quả phẫu thuật.

Mục tiêu: Nghiên cứu vai trò của lưu lượng máu từ thất lên động mạch phổi trong phẫu thuật Fontan với đường dẫn máu ngoài tim bằng ống ghép nhân tạo. loạt ca.

Phương pháp nghiên cứu: tiền cứu, hàng

Kết quả: từ 05/2015 đến $01 / 2019$ có 122 bệnh nhân được phẫu thuật Fontan với đường dẫn ngoài tim bằng ống ghép nhân tạo tại Viện Tim TPHCM, trong đó có 58 trường hợp còn lưu lượng máu từ thất lên ĐMP. Nhóm bệnh nhân còn dòng máu từ thất lên ĐMP có tuổi mổ, $\mathrm{SpO} 2$, áp lực ĐMP trung bình trước mổ, chỉ số Nakata và chỉ số McGoon lớn hơn có ý nghĩa so với nhóm không còn dòng máu từ thất lên ĐMP. Nghiên cứu cho thấy, còn lưu lượng máu từ thất lên ĐMP không làm tăng tỉ lệ tử vong bệnh viện và biến chứng sau mổ.

Kết luận: lưu lượng máu từ thất lên ĐMP giúp phát triển hệ thống ĐMP tốt hơn, tránh được nguy cơ phải mở rộng các nhánh ĐMP và không làm tăng nguy cơ của phẫu thuật Fontan với đường dẫn máu ngoài tim bằng ống ghép nhân tạo

Từ khóa: Phẫu thuật Fontan, lưu luợng máu tì̀ thất lên động mạch phổi.

\section{THE ROLES OF ANTEGRADE-FLOW IN} EXTRA-CARDIAC FONTAN COMPLETION

ABSTRACT:
Background: In Fontan completion for
functional single ventricles, the roles of

ABSTRACT:

functional single ventricles, the roles of

\section{Phạm Hũu Minh Nhựt*, Trần Quyết Tiến **}

antegrade-flow still have a lot of controversies about effects and influences to surgical results.

Objective: we study the roles of AntegrageFlow in Extra-cardiac Fontan completion.

Method: perspective study, serial cases.

Results: From 05/2015 to 01/2019, 122 patients underwent Extra-cardiac Fontan completions at the Heart Institution of Ho Chi Minh city. Antegrade-flows were maintained in 58 patients. Patients with antegrade-flow had significantly higher mean ages at operation, mean $\mathrm{SpO} 2$, mean pulmonary pressures, mean Nakata indices and mean McGoon indices than those without antegrade-flows. Antegrade-Flows did not increase hospital mortality and morbidity.

Conclusion: Antegrade-Flow can possibly develop good pulmonary arterial branches, avoid of pulmonary branches extension and does not increase morbidity and mortality of ECC- Fontan completion.

Keywords: ECC Fontan, Antegrade-Flow

\section{Đă̆t vấn đề:}

Lưu lượng máu từ thất lên động mạch phổi (ĐMP) cùng với các tuần hoàn bàng hệ có vai trò quan trọng trong việc quyết định mức độ tím của các bệnh nhân tim chỉ có một tâm thất chức năng, tuy nhiên nếu lưu lượng này quá nhiều sẽ có nguy cơ gây ra quá tải thể tích trong thời kỳ tiền Fontan và có khả năng ảnh hưởng đến tuần hoàn Fontan sau này[1].

Trong phẫu thuật Fontan cho bệnh tim một tâm thất chức năng hiện nay, vai trò của lưu

\footnotetext{
*Viện Tim TP.Hồ Chí Minh.

** Bộ Môn Phẫu Thuật Tim Mạch và Lồng Ngực, BV Chọ Rẫy Nguời chịu trách nhiệm khoa họ: PGS.TS Trần Quyết Tiến Ngày nhận bài: 28/12/2020 - Ngày Cho Phép Đăng: 22/01/2021
} 
lượng máu từ thất lên động mạch phổi vẫn còn nhiều bàn luận về hiệu quả và các ảnh hưởng đến kết quả phẫu thuật[2].

\section{Mục tiêu:}

Nghiên cứu vai trò của lưu lượng máu từ thất lên động mạch phổi trong phẫu thuật Fontan với đường dẫn máu ngoài tim bằng ống ghép nhân tạo.

\section{Đối tượng và phương pháp nghiên cứu:}

Đối tượng nghiên cứu: các bệnh nhân được phẫu thuật Fontan với đường dẫn máu ngoài tim bằng ống ghép nhân tạo tại Viện Tim TPHCM.

Phương pháp Nghiên cứu: tiền cứu, hàng loạt ca.

Tiêu chuẩn xác định lưu lượng máu từ thất lên ĐMP là bằng siêu âm tim và thông tim chẩn đoán.

Đặc điểm nhóm nghiên cứu:

Từ tháng $05 / 2015$ đến tháng $01 / 2019$ có 122 trường hợp phẫu thuật Fontan với đường dẫn máu ngoài tim cho các bệnh tim bẩm sinh có một tâm thất chức năng. Trong đó có 58 trường hợp $(47,5 \%)$ vẫn còn lưu lượng máu từ thất chung lên ĐMP (antegrade-flow) ở các bệnh nhân có hẹp van động mạch phổi hoặc được làm hẹp ĐMP trước đó, và 64 trường hợp $(52,5 \%)$ bệnh nhân không còn lưu lượng máu từ thất chung lên ĐMP ở các bệnh nhân không có lỗ van ĐMP hoặc thân ĐMP đã được cắt rời trong lần phẫu thuật Glenn hai hướng.

Về đặc điểm dịch tễ, tỉ lệ nam/nữ là 65/57 (53,3\%/46,7\%). Tuổi trung vị là 7,75 Tuổi (nhỏ nhất là 3 tuổi, lớn nhất là 30 tuổi), trong đó tuổi trên 4 tuổi chiếm đa số. Trong nhóm nghiên cứu tất cả các trường hợp đều đã được thực hiện phẫu thuật Glenn hai hướng trước đó. Thời gian trung vị từ lần mổ Glenn đến phẫu thuật Fontan là 6,3 năm (ngắn nhất là 1 năm, dài nhất là 23 năm). Mức độ suy tim trước mổ phân loại theo NYHA, nghiên cứu của chúng tôi có các bệnh nhân chủ yếu là suy tim độ II $(68,9 \%)$. Chỉ có 17 bệnh nhân $(13,9 \%)$ có suy tim độ III và không có bệnh nhân nào suy tim độ IV. Tất cả các bệnh nhân đều có nhịp xoang trước mổ, chức năng tim tốt với $\mathrm{EF}$ $\geq 60 \%$ chiếm tỉ lệ $77 \%$ (94 trường hợp). Tất cả các bệnh nhân đều được phẫu thuật Fontan với đường dẫn ngoài tim bằng ống ghép nhân tạo.

Bảng 1: Đặc điểm truớc mổ của hai nhóm bệnh nhân có và không có luu luợng máu tù̀ thất lên ĐMP.

\begin{tabular}{|c|c|c|c|}
\hline & \multicolumn{2}{|c|}{ Lưu lượng máu từ thất lên ĐMP } & \multirow[b]{2}{*}{ Giá trị P } \\
\hline & có & Không & \\
\hline & (58 bệnh nhân) & (64 bệnh nhân) & \\
\hline Tuổi (năm) & $11,6 \pm 5,9$ & $7, \dot{4} \pm 4,4$ & $<0,001^{\mathrm{b}}$ \\
\hline Thời gian từ Glenn đến Fontan(năm) & $7,7 \pm 4,6$ & $5,0 \pm 2,9$ & $<0,001^{\mathrm{b}}$ \\
\hline Cân nặng (Kg) & $30,86 \pm 12,5$ & $23,49 \pm 9,94$ & $0,001^{\mathrm{b}}$ \\
\hline Chiều cao $(\mathrm{cm})$ & $133,84 \pm 22,5$ & $116,05 \pm 19,33$ & $<0,001^{\mathrm{b}}$ \\
\hline $\mathrm{SpO} 2(\%)$ & $77,12 \pm 5,45$ & $74,44 \pm 5,6$ & $0,006^{\mathrm{a}}$ \\
\hline Chỉ số tim/lồng ngực & $0,57 \pm 0,06$ & $0,56 \pm 0,06$ & $0,36^{\mathrm{a}}$ \\
\hline Dung tích hồng cầu(\%) & $54,4 \pm 8,0$ & $54,2 \pm 6,6$ & $0,95^{\mathrm{a}}$ \\
\hline Huyết sắc tố $(\mathrm{g} / \mathrm{dl})$ & $17,9 \pm 3,0$ & $18,0 \pm 2,5$ & $0,91^{\mathrm{a}}$ \\
\hline Phân suất tống máu (\%) & $61,1 \pm 6,4$ & $64,1 \pm 6,5$ & $0,017^{\mathrm{b}}$ \\
\hline Áp lực động mạch phổi trung bình (mmHg) & $12,66 \pm 2,2$ & $11,56 \pm 2,8$ & $0,036^{\mathrm{b}}$ \\
\hline Chỉ số Nakata & $281,23 \pm 96,8$ & $248,34 \pm 82,7$ & $0,028^{\mathrm{b}}$ \\
\hline $\begin{array}{l}\text { Chỉ số Mcgoon } \\
\text { a Phép kiểm T hai nhóm } \\
\text { b Phép kiểm Mann Whitney U }\end{array}$ & $2,3 \pm 0,36$ & $2,1 \pm 0,33$ & $0,006^{\mathrm{b}}$ \\
\hline
\end{tabular}


Bảng 2: Đặc điểm bệnh nhân có và không có lưu lương máu tù thất lên ĐMP trong và sau mổ:

\section{Lưu lượng máu từ thất lên ĐMP}

(58 bệnh nhân)

Thời gian THNCT(phút)

Dung tích hồng cầu sau mổ(\%)

Huyết sắc tố sau mổ $(\mathrm{g} / \mathrm{dl})$

Áp lực ĐMP trung bình sau ngưng THNCT (mmHg)

Áp lực nhĩ chung sau ngưng THNCT (mmHg)

Chênh áp qua phổi sau ngưng THNCT $(\mathrm{mmHg})$

$\mathrm{SaO} 2(\%)$

${ }^{a}$ Phép kiểm T hai nhóm

${ }^{\mathrm{b}}$ Phép kiểm Mann Whitney U có

không

Giá trị P

(64 bệnh nhân)

$\begin{array}{ccc}139,05 \pm 42,8 & 132,20 \pm 40,87 & 0,34^{\mathrm{b}} \\ 43,3 \pm 5,4 & 42,3 \pm 4,9 & 0,21^{\mathrm{a}} \\ 14,2 \pm 1,8 & 13,8 \pm 1,6 & 0,20^{\mathrm{a}} \\ 15,6 \pm 2,7 & 15,4 \pm 2,5 & 0,79^{\mathrm{a}} \\ 7,2 \pm 1,8 & 7,0 \pm 1,8 & 0,80^{\mathrm{a}} \\ 8,4 \pm 1,7 & 8,4 \pm 1,8 & 0,70^{\mathrm{a}} \\ 92,6 \pm 3,5 & 91,2 \pm 4,0 & 0,03^{\mathrm{a}}\end{array}$

Bảng 3: Mối liên quan giũua luu lượng máu tù thất và mở rộng nhánh trong lần phẫu thuật Fontan

\begin{tabular}{|c|c|c|c|c|c|}
\hline & & \multicolumn{2}{|c|}{ Mở rộng nhánh } & \multirow[b]{2}{*}{ Tổng số } & \multirow[b]{2}{*}{ Giá trị $\mathbf{P}$} \\
\hline & & không & có & & \\
\hline \multirow{3}{*}{$\begin{array}{l}\text { lưu lượng máu từ } \\
\text { thất lên ĐMP }\end{array}$} & Không & 39 & 25 & 64 & $X^{2}=7,08$ \\
\hline & Có & 48 & 10 & 58 & $\mathrm{P}=0,009$ \\
\hline & Tổng số & 87 & 35 & 122 & \\
\hline
\end{tabular}

Phép kiểm Chi bình phương cho thấy có mối liên quan có ý nghĩa giữa lưu lượng máu từ thất lên ĐMP và mở rộng nhánh trong lần phẫu thuật Fontan. Các bệnh nhân còn lưu lượng máu này có tỉ lệ mở rộng các nhánh ĐMP thấp hơn có ý nghĩa so với các bệnh nhân không còn.

\section{KẾT QUẢ:}

Tử vong bệnh viện (bao gồm các trường hợp tử vong trong vòng 30 ngày hoặc trong thời gian còn nằm viện). Tỉ lệ tử vong bệnh viện là $9,8 \%$ (12/122 trường hợp).

Bảng 4: So sánh tỉ lệ tử vong giũa nhóm có và không có lưu lương máu tù thất lên ĐMP trong phẫu thuật Fontan với đường dẫn máu ngoài tim

\section{Tử vong bệnh viện}

$\begin{array}{lcccc} & & \text { Có } & \text { Không } & \text { Tổng cộng } \\ \text { Lưu lượng máu } & \text { Có } & 6 & 52 & 58 \\ \text { từ thất lên ĐMP } & \text { Không } & 6 & 58 & 64 \\ & \text { Tổng cộng } & 12 & 110 & 122 \\ \text { P value (Fisher'exact test) } & & & 0,85 & \end{array}$


Bảng 5: Đặc điểm hậu phẫu của hai nhóm có và không có luu luợng máu tù̀ thất lên ĐMP (loại trù các trường hợp tử vong)

Dòng máu từ thất lên ĐMP

(52 bệnh nhân)

Thời gian thở máy(ngày)

Thời gian nằm hồi sức(ngày)

Thời gian rút ống dẫn lưu (ngày)

Thời gian nằm viện(ngày)

Phân suất tống máu (\%) khi xuất viện

${ }^{a}$ Phép kiểm T hai nhóm

${ }^{\mathrm{b}}$ Phép kiểm Mann Whitney U có

không

(58 bệnh nhân)

$\begin{array}{ccc}3,6 \pm 5,1 & 3,3 \pm 6,7 & 0,27^{\mathrm{b}} \\ 6,4 \pm 6,7 & 7,1 \pm 8,4 & 0,30^{\mathrm{b}} \\ 13,37 \pm 8,0 & 14,88 \pm 11,6 & 0,80^{\mathrm{b}} \\ 23,50 \pm 12,4 & 24,74 \pm 16,3 & 0,99^{\mathrm{b}} \\ 61,79 \pm 4,9 & 63,07 \pm 6,2 & 0,36^{\mathrm{a}}\end{array}$

Giá trị P
, $27^{\mathrm{b}}$
0,30
$0,99^{\mathrm{b}}$

$0,36^{\mathrm{a}}$

Bảng 6: Biến chứng sau mổ phẫu của hai nhóm có và không có luu luợng máu tù̀ thất lên ĐMP

\section{Dòng máu từ thất lên ĐMP}

có không

Giá trị P

(58 bệnh nhân)

(64 bệnh nhân)

Hội chứng cung lượng tim thấp 22

Suy thận (thẩm phân phúc mạc)

Tràn dịch dưỡng trấp 12

Viêm phổi

Xuất huyết não

Nhiễm trùng huyết

Nhiễm trùng xương ức

Nhiễm trùng vết mổ

Tăng áp phổi

Để hở xương ức sau mổ

Suy gan cấp

Choáng giảm thể tích nặng

Rối loạn nhịp nhĩ (Rung nhĩ, SAT, cuồng nhĩ)

Máu đông màng phổi

Chảy máu

Liệt cơ hoành

Dẫn lưu màng phổi kéo dài (>14 ngày)

${ }^{\mathrm{c}}$ phép kiểm Chi bình phương

${ }^{\mathrm{d}}$ phép kiểm chính xác Fisher 


\section{BÀN LUẬN:}

Các bệnh tim chỉ có một tâm thất chức năng có thể chỉ hẹp van động mạch phổi hoặc có thân ĐMP và van ĐMP phát triển bình thường được làm hẹp bớt ĐMP trước hoặc trong lần phẫu thuật Glenn. Trong các trường hợp này vẫn còn dòng máu từ thất lên ĐMP với lưu lượng khác nhau tùy theo mức độ hẹp của van ĐMP [3].

Trong thời kỳ đầu, đối với các bệnh tim bẩm sinh chỉ có một tâm thất chức năng thì phẫu thuật Glenn hai hướng kết hợp với việc duy trì lưu lượng máu từ thất lên động mạch phổi (ở các trường hợp chỉ hẹp van ĐMP hoặc làm hẹp bớt ĐMP) cũng được xem là một giải pháp gần triệt để nhất là trong các trường hợp Fontan có nguy cơ. Tuy nhiên theo thời gian thì giải pháp này được xem như một giai đoạn chuyển tiếp đến Fontan vì hiệu quả ưu việt của tuần hoàn Fontan đem lại khả năng gắng sức tốt hơn[4]. Vai trò của dòng máu từ thất lên ĐMP giúp cho bệnh nhi không quá tím và có lợi trong việc phát triển hệ thống động mạch phổi cho phẫu thuật Fontan[5]. Bằng phép kiểm có dấu Wilcoxon cho các biến số định lượng không có phân phối chuẩn, chúng tôi thấy chỉ số Nakata và chỉ số McGoon trong nhóm còn lưu lượng máu lên ĐMP lớn hơn có ý nghĩa so với nhóm không còn lưu lượng máu lên ĐMP. Như vậy có thể nhận định là nếu lưu lượng máu này được để lại đúng tiêu chuẩn sẽ giúp làm phát triển hệ thống ĐMP tốt và đồng đều hơn. Nhờ sự phát triển hệ ĐMP tốt nên các bệnh nhân trong nhóm còn lưu lượng máu từ thất lên ĐMP có tỉ lệ phải mở rộng nhánh ĐMP thấp hơn có ý nghĩa so với nhóm không còn (bảng 3). Qua nghiên cứu, chúng tôi nhận thấy việc để lại lưu lượng máu từ thất lên phổi có lợi ích cho việc trì hoãn phẫu thuật Fontan nhất là ở các trẻ nhỏ cân mà không bị tím quá nặng và không bị phát triển các tuần hoàn bàng hệ bất lợi.

Tuy nhiên việc để lại một nguồn máu lên phổi quá mức có thể góp phần làm tăng gánh thể tích thất chung và làm hở van nhĩ thất nặng hơn nếu thời gian từ phẫu thuật Glenn đến phẫu thuật Fontan kéo dài. Nghiên cứu của tác giả Tao Zhang và cộng sự cho thấy nếu chỉ duy trì dòng máu lên phổi từ thất cho các trường hợp phải banding động mạch phổi mà áp lực động mạch phổi trung bình sau banding $\leq 15 \mathrm{mmHg}$ thì có ưu điểm là vẫn duy trì độ bão hỏa ôxy tốt, không bị biến chứng hình thành các bất thường thông nối động-tĩnh mạch phổi do vẫn duy trì dòng máu từ gan lên hai phổi và tránh được sự quá tải thể tích[6]. Tác giả Samuel L. Casella và cộng sự cho rằng nếu sau phẫu thuật Glenn nếu một bên nhánh động mạch phổi bị hẹp mà không có thêm dòng máu từ thất thì có thể sử dụng một Blalock nhỏ từ động mạch chủ vào bên nhánh thiểu sản mà không làm tăng áp lực động mạch phổi và không làm mất hiệu quả của dòng máu từ Glenn shunt[7].

Nghiên cứu của chúng tôi có 58 trường hợp $(47,5 \%)$ vẫn còn lưu lượng máu từ thất chung lên ĐMP (antegrade flow) ở các bệnh nhân có hẹp van động mạch phổi hoặc được làm hẹp động mạch phổi trước đó. Chúng tôi luôn áp dụng áp lực động mạch phổi trung bình $\leq 15 \mathrm{mmHg}$ để không làm tăng gánh thể tích thất chung và không làm ảnh hưởng dòng máu từ các $\mathrm{TMC}$ trên vào ĐMP giúp Glenn shunt hoạt động tốt.

Theo nghiên cứu của tác giả Trần Đắc Đại tại Viện E (2020) cho 145 bệnh nhân được phầu thuật Fontan từ 08/2012 đến 12/2019, cho thấy còn lưu lượng máu từ thất lên ĐMP là một trong các yếu tố dự báo nguy cơ độc lập cho biến chứng tràn dịch màng phổi kéo dài sau phẫu thuật Fontan (các trường hợp dẫn lưu màng phổi > 14 ngày)[8]. Tuy nhiên nghiên cứu của chúng tôi chưa tìm ra mối liên quan có ý nghĩa này (bảng 6).

Khi phẫu thuật với các trường hợp còn lưu lượng máu từ thất lên thân ĐMP, chúng tôi thường cắt rời thân động mạch phổi để tận dụng phần hợp lưu của hai nhánh động mạch để nối với ống ghép. Đối với đầu gần chúng tôi thường xử lý không cần liệt tim bằng các mũi khâu cột có miếng đệm sát với vùng vòng van động mạch phổi để tránh túi phình, một chọn lựa khác trong trường hợp không đảm bảo khâu sát với vòng van động mạch phổi là làm liệt tim và mở đầu gần khâu kín vòng van động mạch phổi từ bên trong với gia cố thêm bên ngoài và nhất thiết cần lưu ý không được để lại khoảng chết giữa hai đường may để tránh chảy máu và nguy cơ tạo túi phình. Tác giả Ujjwal Kumar Chowdhury và cộng sự cũng nhấn mạnh việc xử lý thân động mạch phổi nên cắt rời không nên cột để tránh 
biến chứng tạo túi phình phía dưới chỗ cột[9]. Ngoài ra nếu cột đơn thuần không cắt rời sẽ có nguy cơ tạo huyết khối trong hệ thống ĐMP và cũng có nguy cơ dòng máu được tái lập trở lại và gây suy tuần hoàn Fontan[10].

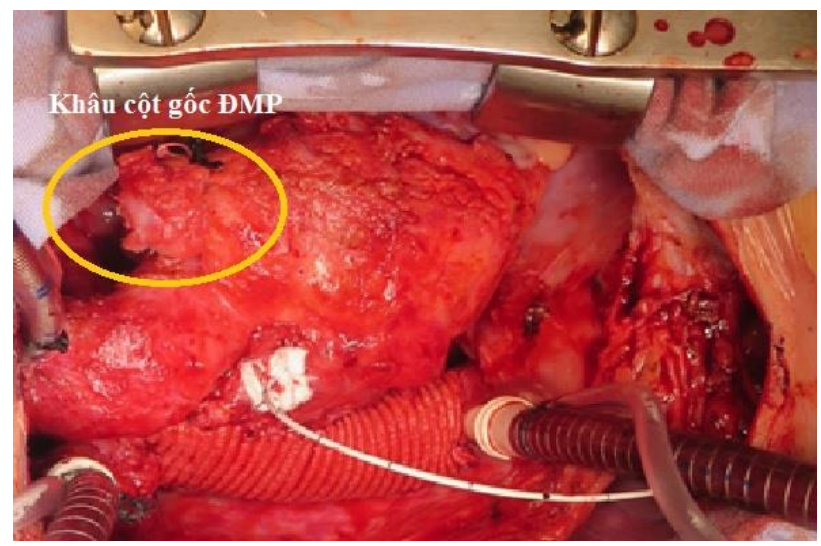

Hình 1: Khâu cột gốc ĐMP trong phẫu thuật Fontan

Phân tích hồi qui đơn biến trong nghiên cứu của chúng tôi cũng cho thấy không có sự khác biệt có ý nghĩa về tỉ lệ tử vong giữa nhóm còn lưu lượng máu từ thất lên động mạch phổi và nhóm không còn lưu lượng máu lên phổi (bảng 4). Nghiên cứu của chúng tôi cũng cho thấy không có sự khác biệt có ý nghĩa về các thông số hậu phẫu và biến chứng trong hai nhóm này (bảng 5 và 6 ).

\section{KẾT LUẬN:}

Lưu lượng máu từ thất lên ĐMP nếu được duy trì hợp lý (áp lực ĐMP trung bình $\leq 15$ $\mathrm{mmHg}$ ) không phải là một yếu tố nguy cơ của phẫu thuật Fontan với đường dẫn máu ngoài tim bằng ống ghép nhân tạo.

Duy trì lưu lượng máu từ thất lên ĐMP giúp bệnh nhân tim chỉ có một tâm thất chức năng phát triển hệ thống ĐMP tốt hơn, tránh được nguy cơ phải mở rộng các nhánh ĐMP và có thể cho phép trì hoãn thời gian phẫu thuật Fontan

\section{TÀI LIỆ THAM KHẢO:}

1. Jonas RA, Single Ventricle, in Comprehensive Surgical Management of Congenital Heart Disease. 2004, Hodder Arnold: London. p. 357-385.

2. Ferns, S.J., et al., Is additional pulsatile pulmonary blood flow beneficial to patients with bidirectional Glenn? J Thorac Cardiovasc Surg, 2013. 145(2): p. 451-4.

3. Corno, A.F., Editorial: Univentricular Heart. Frontiers in Pediatrics, 2015. 3(75).
4. Talwar, S., et al., Exercise performance after univentricular palliation. Annals of Pediatric Cardiology, 2018. 11(1): p. 40-47.

5. Sughimoto, K., et al., Forward Flow Through the Pulmonary Valve After Bidirectional Cavopulmonary Shunt Benefits Patients at Fontan Operation. Ann Thorac Surg, 2015. 100(4): p. 1390-6; discussion 1396-7.

6. Zhang, T., et al., Uncontrolled Antegrade Pulmonary Blood Flow and Delayed Fontan Completion After the Bidirectional Glenn Procedure: Real-World Outcomes in China. The Annals of Thoracic Surgery, 2016. 101(4): p. 1530-1538.

7. Casella, S.L., et al., Targeted Increase in Pulmonary Blood Flow in a Bidirectional Glenn Circulation. Seminars in Thoracic and Cardiovascular Surgery, 2018. 30(2): p. 182-188.

8. Tran, D.D., et al., Predictors of Prolonged Pleural Effusion After the Extracardiac Fontan Procedure: A 8-Year Single-Center Experience in Resource-Scare Setting. Pediatr Cardiol, 2020.

9. Chowdhury, U., et al., Bidirectional Glenn with interruption of antegrade pulmonary blood flow: Which is the preferred option: Ligation or division of the pulmonary artery? Annals of Cardiac Anaesthesia, 2016. 19(3): p. 561-563.

10.Li, D., et al., Successful transcatheter closure of residual ventriculopulmonary blood flow with muscular VSD occluder after ligation of pulmonary trunk in Fontan procedure. International Journal of Cardiology, 2015. 191: p. 277-278. 